\title{
Adaptation, Culture, and the Energy Transition in American Coal Country
}

\begin{abstract}
The U.S. coal industry has experienced economic decline over the past several decades, which has resulted in a loss of mining jobs and severe economic hardship in many coal communities. Recent efforts to relax environmental regulations are ostensibly intended to help relieve this hardship and to revitalize this industry. Based on evidence gathered from focus groups and interviews conducted in U.S. coal communities, we argue that coal communities that have experienced mine closures have already begun an economic and social transition, one that is based on reshaping their culture and sense of identity, and false promises to return coal jobs can be destructive to the progress that has been made.
\end{abstract}

Keywords: Coal Communities, Energy Transition, Environmental Regulations, Energy Policy

Published version

Energy Research \& Social Science

Volume 37, March 2018, Pages 133-139

https://doi.org/10.1016/j.erss.2017.10.007 
The United States is undergoing an energy transition. An energy transition is marked by a shift from an economic system dependent on one set of resources and technologies to another ${ }^{1}$. In the present case, the shift is from dependence on carbon-intensive energy resources to lower carbon alternatives. While historic energy transitions have often taken up to a century to unfold ${ }^{2,3}$, the current U.S. transition is evolving at a relatively rapid pace.

Certain areas and industries may be lost in such a transition ${ }^{4}$ and the coal industry has been one of the primary sectors affected adversely. Early signs emerged of coal industry transition and decline $\mathrm{e}^{5,6}$ as recently as two decades ago due to advanced mechanization, declining mining productivity, and environmental regulations ${ }^{7}$. Over the last decade, however, as domestic electricity demand has declined and market substitutes such as natural gas, wind, and solar have dropped in price, the coal industry decline has become precipitous.

Within his first three months in office, President Trump signed a bill to repeal a regulation protecting streams from coal mining waste and an executive order to rescind limits on greenhouse gas (GHG) emissions from existing coal power plants (i.e., the Clean Power Plan), lift potential restrictions on coal mining on federal lands, and remove the mandate to include the social cost of carbon in regulatory benefit-cost analyses. These and other actions fulfilled campaign promises he made to bring back U.S. coal jobs. It is unlikely, however, that these policy changes will drastically affect the country's current energy transition. While environmental regulations have been an important factor in the energy transition, they are not the primary reason for the recent decline of the coal industry. Thus, proposed efforts to remove environmental regulations, all else constant, will not change the near- or long-term economic trajectories for coal communities.

Based on insights gathered from focus groups in Appalachian coal mining communities and interviews with professionals working within these communities, as conducted in the summer of 2016, we present an argument in this Perspectives article that many within Appalachian coal communities understand that coal is a declining industry, and that it is important to seek out new economic opportunities and redefine their identity. Significant efforts are already underway on both a community 
and individual level to adapt to these changes, and signaling that coal should remain an important part of the U.S. fabric can impede momentum.

This article stresses the importance of asking questions about the distribution of benefits and burdens resulting from the U.S. energy transition. The article complements a growing literature on the "just" transition, which emphasizes the need for the transition to be experienced equitably across groups

and communities ${ }^{8,9,10,11}$. The article also underscores the importance of understanding what is transpiring in declining communities, and the manner in which such communities approach or perceive the energy transition.

\section{Background: The Decline of the U.S. Coal Industry and Economic Vulnerability}

Both U.S. coal mining and electricity production jobs, as well as coal production are declining. Coal mining jobs have decreased approximately $71 \%$ since 1985 , with an estimated 170,500 jobs in January, 1985, and 50,000 in January, 2017 $7^{12}$. Coal production peaked in 2011 and has dropped dramatically since then $^{7}$. Figure 1 displays the difference in coal employment between 2011 and 2015, the most recent year of available data. Despite some gains in jobs in certain counties, this map highlights that Appalachia, the focus of this Perspectives article, was one of the hardest hit regions.

\section{[Insert Figure 1]}

These declining trends are due to a confluence of factors. Among the earlier contributors were 1) rising prices for coal due to declining mining productivity, the need to dig deeper for usable coal deposits, and rising costs of sub-surface coal mining ${ }^{13,7,14}$;2) the mechanization of coal mining in which, even as production has expanded, technological improvements have led to higher worker productivity and fewer jobs $^{5}$; and 3) environmental regulations ${ }^{13,14}$, especially the sulfur dioxide limits in the Clean Air Act of 1990 and the subsequent decline in demand for Appalachia's high-sulfur coal ${ }^{6}$. A recent analysis argued that environmental regulations have played a role in the decline of the coal industry, but that the role has been quite modest relative to other factors. This study estimated that recent environmental regulations only accounted for about $3.5 \%$ of the total $33 \%$ decline in U.S coal production ${ }^{15}$. 
Three additional trends have played a particularly important role over the past decade. First, U.S. demand for electricity has been relatively flat since falling drastically at the end of the last decade during the Great Recession. Forecasts suggest that it is not expected to appreciably increase for decades to come $^{16}$.

Second, the price of market substitutes has fallen considerably. As a result of the U.S. shale gas revolution, natural gas prices are well below the price per unit of coal across most of the country. The cost of wind and solar generation has also declined significantly due to technological improvements ${ }^{17}$ and there is little to suggest that these price trends will change considerably in the future. To illustrate the challenges to the current U.S. market for coal, Figure 2 maps counties according to the resource that would produce the lowest levelized cost of electricity (LCOE) in the construction of new power plants based on a set of assumptions available in Rhodes et al. ${ }^{18}$. This map shows that even with a zero social cost of carbon, coal is not economically competitive for electricity applications anywhere in the country. Although an LCOE metric is not the perfect measure to compare across different types of resourcesparticularly between dispatchable and non-dispatchable resources - nor does it account for the need to have back-up resources for intermittent sources, it provides some evidence about the relative competitiveness of different energy resources.

These price differentials have important implications for utility and infrastructure planning. Electricity investments tend to be long-term, since power plants are built to last 30-40 years. As utilities and power producers invest in new facilities, they will weigh the cost of different energy resources, both present and based on future projections. As of January 2017, out of the approximately 110,000 MW capacity that is under development or planned through 2027, approximately one percent is coal. Meanwhile, between 2012 and 2015 alone, 34,000 MW of coal-fired power generation capacity went offline. $^{19}$

\section{[Insert Figure 2]}

Third, many countries are adopting low-carbon alternatives and have committed to the Paris Climate Agreement, as displayed in Figure 3. Although the President Trump has declared his intention to 
withdraw the United States from the agreement, many U.S. state and local governments have noted their continued commitment to renewable energy development and GHG abatement. A large number of other countries have also committed internally to the pursuit of renewable energy through renewable portfolio standards and feed-in tariffs ${ }^{20}$. Canada and Finland have banned coal generation by specific target years and all EU countries save Greece and Poland have committed to no more new coal power plants after 2020. The International Energy Agency forecasts that total global demand for renewable energy sources will continue to rise while the demand for coal will stall ${ }^{21}$.

[Insert Figure 3]

These trends suggest a bleak long-term forecast for coal as a market commodity, regardless of retrenchment of relevant U.S. environmental regulations ${ }^{22}$. Moreover, for a number of reasons, coal communities are particularly vulnerable in the face of an evolving energy transition. Due to the historic nature of economic development within coal mining communities, they are especially prone to economic hardship in boom to bust periods. U.S. coal communities are marked by a dependence or resource curse ${ }^{23}$, which is defined as a tendency for communities that rely heavily on certain extractive resources to become "addicted" to these resources and to develop overly dependent or specialized economies.

Many coal regions have had mono-industry economies for over a century. Higher wages for the resource commodity crowd out growth in other industries ${ }^{23}$. The nature of coal mining jobs, which are highly unionized and high paying, tends to reinforce this dependency and provide little incentive for regions with coal resources to diversify their economies and employment opportunities, or foster entrepreneurship $^{24}$. Such mono-industry economies make it more difficult for communities to adapt to shocks $^{25,26}$ due to a lack of alternative labor market options and a consistent underinvestment in education $^{27}$. In addition, when coal extraction declines, it also affects the entire community, since their local governments rely on severance taxes to support education and other public services.

Not only do these communities offer a dearth of economic opportunities, but individuals within these communities may limit their own educational attainment. The allure of a low-skilled, high-paying profession often results in coal miners beginning their careers before completing high school ${ }^{23,28}$. Lower 
levels of educational attainment across coal miners and their families further render them susceptible to shocks, and limit the potential for adaptability in the face of economic decline.

\section{Methodological Approach}

This analysis draws from in-depth focus groups and interviews conducted with individuals that reside or work within the range in Appalachia identified in Figure 4. Questions in the focus group focused on whether and how respondents conceive of the energy transition, what implications this transition has for their personal circumstances, and how they have fared as the transition has evolved in their own communities. The focus group sessions were followed by a short survey that participants completed before departing. The interview questions addressed perceptions of an energy transition, how the respondent was involved in this transition, and what they had observed within their communities.

\section{[Insert Figure 4 here]}

The interviews and focus groups were conducted in July, 2016. Interviewees were identified via extensive online searching as well as preliminary phone calls to ask for contacts. Subsequent respondents were identified via snowball sampling. For the focus groups, we partnered with local organizations that worked with former coal miners and coal mining communities in one way or another. Both focus groups and the majority of interviews were conducted in person. The focus groups lasted around one hour. As compensation for focus group participants, we offered \$25 gift cards to the local grocery and household store, which, in the case of both focus groups, was a Walmart. All sessions were recorded with the permission of the participants and then transcribed.

The two focus groups had slightly different groups of participants. The first focus group ( $n=9)$, conducted in Williamson, West Virginia, included some unemployed former coal miners, as well as additional community members including the wife of a coal miner and part-time retail workers, among others. These participants did not formerly know each other. The second focus group $(n=16)$, conducted in Ghent, West Virginia, consisted of a group of former coal miners that had been laid-off but returned to a technical training program. These participants already knew each other from this program. In total, 25 
individuals participated in the focus group session. Table 1 provides basic descriptive statistics about the focus group participants.

[Insert Table 1 here]

Interview participants included those that worked for training or educational programs, economic development units, social enterprises, community-based and/or religious organizations, industries that seek former coal miners as employees, foundations that support revitalization activities within the region, analysts, and those that work within the media industry. Table 2 documents participants' professional affiliations. We interviewed a total of 23 experts. Interviews lasted an average of 38 minutes.

[Insert Table 2 here]

In the Supplementary Information, we provide quotes from the interviews and focus groups that support the arguments made in the present analysis (Supplementary Information Tables 1 and 2). These tables are not exhaustive but, rather, are intended to provide illustration of the various themes highlighted in the section below. In addition, in the Supplementary Information we present word counts and percentages of respondents that mentioned key words covered in this analysis (Supplementary Information Table 3).

\section{Local Perceptions of the Energy Transition}

Interviews and focus groups conducted within Appalachia revealed important insights about how communities are adapting in the current energy transition. These results highlight the importance of culture, shifting mindsets, and community efforts. They also underscore just how potentially damaging it is to make promises about reviving the coal industry.

\section{Coal as culture}

Mining employment in many coal regions dates back over a century. Many of the respondents that participated in this study noted that their grandfather and great-grandfather both worked in the mining industry, so it was a natural decision for them also become a miner. This history and personal identity 
makes it difficult to accept change, as one focus group respondent noted, "People don't like change, especially around here, they been doing the same thing for 150 years, why would they change now?"

The historic roots of coal not only steer individuals toward the profession but also shape the broader culture within these communities. Scholars have identified previously that a strong sense of identity to extractive industries is common ${ }^{5}$, and we found significant evidence of coal culture in Appalachia. Coal was frequently framed as the common bond — or identity — that held the entire community together. This sense of identity is amplified by strong attachments to location, landscape, and personal networks, which not only makes it challenging for individuals to generate a conception of self that transcends coal, but also makes it particularly difficult psychologically for individuals that need to leave Appalachia for new employment opportunities. One respondent explained:

There is also a sense of grief that comes along with it, you know, coal mining is really a part of the culture here and it's interwoven into the way people feel about themselves and their own identity and their identity as a community. And so to lose that so quickly is really, it creates a sense of grief among people about losing their way of life and a piece of their culture that is really engrained and a part of who they are.

\section{Community Adaptive Capacity}

Despite the prominence of coal in the culture of these communities, many respondents recognized that a transition was underway. The majority of respondents conceived of this transition as permanent, as one focus group participant noted about the future of coal: "I can tell you what my grand-daddy always said, no matter how many times you beat and kick that dead horse, it's not getting up to plow again."

The coal industry decline has affected individuals and families differently. Yet a fairly consistent story emerged from the focus groups and interviews about how former coal miners have fared. Many began by noting that their unemployment came suddenly and unexpectedly. Once their jobs disappeared, many lived off of their savings, credit, or unemployment benefits while seeking employment or waiting until their former positions were reinstated. 
For those that enter training or community college programs, the challenge is to stay financially afloat before the opportunity arises again to secure an income. Many of the experts that work within the community colleges discussed the bartering system that students have devised to exchange items such as eggs and produce, and one respondent noted that he/she has loaned students money on several occasions for interview clothes.

The new professional opportunities mentioned by the respondents include electricity lineman, solar installer, wind installer, truck driver, or working within the tourism or construction industries. Not all of these jobs, however, are available locally, with some requiring them to travel for hours to get to their work site and to spend several days at a time away from home. These conditions highlight the lack of alternative economic opportunities within many coal communities. Unemployed workers must then contend with the difficult challenge of waiting to see if future opportunities arise or to uproot what can be deep community linkages by moving to seek job opportunities elsewhere.

When the transition began, it was marked by much anger and resentment. Many noted, however, that that anger has been replaced by excitement about new opportunities, and the recognition that the transition is real and inevitable, even if challenging. As an example, one respondent commented on the attitudes of solar installation trainees toward the energy transition: "Honestly, I think most of them are really excited... You could ask a lot of them, and they'll say that. Coal is probably not coming back, or if it is, it's not what it once was, so I'm going to learn as much new and exciting things as I can, I want to get a degree, so I'm more hirable later on."

Another respondent described the evolving optimism: "I think West Virginia is always a collective of its geography. The hills and the valleys, the highs and the low, the good and the bad, I think there is - at times I have tremendous optimism that we will see our way through this and I think that optimism is shared...At other times, I think it's going to be really hard, this is going to be a difficult...transition." What then leads to a change in mindset in which an individual switches from a perspective of anger to one of motivation? 


\section{Shifting Mindsets and Seeking New Opportunities}

Many respondents discussed how a primary component of an individual's or a community's ability to adapt is to embrace the move away from a culture of coal rooted in dependence to one focused on new opportunities and community engagement. For many study participants, this vision highlighted the importance of rebuilding with new objectives. One respondent articulated this vision by explaining, "I think longer term, it is an opportunity despite all the pain that people feel to finally diversify our economy, to be healthier, and diversify how we create energy ourselves, to be a kind of a healthier, more vibrant place."

Individuals noted that the changing culture and rising optimism was particularly driven by younger generations. One respondent explained, "I'm beginning to see some real enthusiasm, particularly among young people in small communities in West Virginia, to begin looking for something beyond, something beyond coal." And another noted:

I think slowly but surely, you kind of go through all these stages of mourning. So there's still those that think coal will come back. But there's more than ever in my lifetime many that say it's not coming back, at least not how it was and so there is, definitely more among the younger than among the older, but there is kind of this excitement and possibility, that now coal is gone and we can rebuild our economy into what we want.

Many respondents noted that this remaking of image and economic opportunity has been a collective effort, and that these new bonds contribute positively to the community. An interviewee articulated these sentiments as follows:

The phenomenon ... has been very good to observe. A lot of community groups, a lot of technical systems providers, a lot of university folks, and a lot of nonprofits, and even some businesses that have begun to collaborate now. Around what are the opportunities, possibilities for working in these coal-impacted communities. We...wouldn't have seen this two years ago, much less 5 years ago or 10 years ago. Everybody was in their own domain and weren't necessarily talking to each other... And I think to see positive, sort of small positive successes grows even larger success.

These varied accounts underscore that significant change is already underway in Appalachian coal communities. As many come to terms with the future prospects for coal, the tenor has, at least for 
some, turned from anger to excitement, and the result has been important momentum toward individual and community adaptation.

\section{Discussion and Concluding Arguments}

As the coal industry continues to decline, it is important to consider how best to support the communities that have traditionally relied on coal jobs for their livelihoods. Promising coal communities a return of their jobs has the potential to fill them with false hope, which can threaten the very progress that has been made to date as individuals and communities work to redefine their collective identity and create new, dynamic, and promising opportunities for their future.

It is, of course, important to note that if, despite all present trends, there is a substantial and sustained resurgence in demand for coal, the decline of the industry might slow and could lead to at least a temporary delay in the economic and social transition of U.S. coal communities. One might even argue that with a revival of the coal industry, those that live and work in these communities would be better off than they are currently. Yet, one of the central arguments of this article is that rolling back recent environmental regulations will not lead to a significant resurgence of the coal industry in the United States, since these regulations have played only a minor role relative to slowing demand for electricity and the availability of cheaper and cleaner sources of energy.

Rather than repeal environmental regulations that benefit many Americans, including coal communities themselves $^{5,29}$, and may only result in modest impacts on the long-run vitality of the coal industry ${ }^{22}$ government efforts should help these communities find and harness new economic opportunities. These regions require targeted efforts aimed at economic and human development, and an emphasis on health and education, professional opportunities, and public services. This transition will, by no means, be easy. But, supporting coal communities through the broader energy transition, and offering them the opportunity to recreate their sense of identity and culture, is critical.

Across the diverse communities we examined and stakeholders we interviewed, we found a mostly consistent thread of acceptance and awareness of the energy transition. Respondents understood 
that the coal industry is in decline, and that the United States is transitioning toward lower carbon energy resources. But it is striking that so many individuals addressed the innate cultural perceptions inherent in their communities as a fundamental challenge - this presents a vexing problem for policy makers and decision-makers because arguably it is easier to implement a job training program through investment of financial resources than it is to change long-standing mindsets of individuals with deep ties to a place and economic past.

Although this study is based on a small and deliberate sample, and the findings may not be generalizable to other coal communities or declining communities more generally, our analysis points to the importance of moving beyond political rhetoric to careful consideration to how individuals and communities may be adversely affected by the energy transition. Moreover, the article emphasizes the importance of understanding how they can cope and adapt, and how new opportunities can be created and embraced among those most affected. We believe it is imperative that scholars focus more attention on identifying and evaluating approaches designed to help those adversely affected through the transition. 


\section{References}

1. Fouquet, R., \& Pearson, P. J. Past and prospective energy transitions: insights from history. Energy Policy 50, 1-7 (2012).

2. Grubler, A. Energy transitions research: Insights and cautionary tales. Energy Policy 50, 8-16 (2012).

3. Fouquet, R. The slow search for solutions: Lessons from historical energy transitions by sector and service. Energy Policy 38, 6586-6596 (2010).

4. Hernández, D. Sacrifice along the energy continuum: A call for energy justice. Environmental Justice 8,151-156 (2015).

5. Bell, S. E. \& York, R. Community Economic Identity: The Coal Industry and Ideological Construction in West Virginia. Rural Sociology 75, 111-43 (2010).

6. Lobao, L., Zhou, M., Partridge, M., \& Betz, M. Poverty, place, and coal employment across Appalachia and the United States in a new economic era. Rural Sociology 81, 343-386 (2016).

7. Tierney, S. F. The U.S. coal industry: Challenging transitions in the $21^{\text {st }}$ century (2016).

8. Newell, P., \& Mulvaney, D. The political economy of the 'just transition'. The Geographical Journal 179, 132-140 (2013).

9. Miller, C. A., Iles, A., \& Jones, C. F. The social dimensions of energy transitions. Science as Culture 22, 135-148 (2013).

10. Jenkins, K., McCauley, D., Heffron, R., Stephan, H., \& Rehner, R. Energy justice: A conceptual review. Energy Research \& Social Science 11, 174-182 (2016).

11. Sovacool, B. K., \& Dworkin, M. H. Energy justice: Conceptual insights and practical applications. Applied Energy 142, 435-444 (2015).

12. Federal Reserve Bank of St. Louis. All employees: Mining and Logging: Coal Mining. https://fred.stlouisfed.org/series/CES1021210001 (2017).

13. Haerer, D., \& Pratson, L. Employment trends in the U.S. electricity sector, 2008-2012. Energy Policy 82: 85-98 (2015). 
14. Brown, M. A., Li, Y., Massetti, E., \& Lapsa, M. U.S. sulfur dioxide emissions reductions: Shifting factors and a carbon dioxide penalty. The Electricity Journal 30: 17-24 (2017).

15. Houser, T., Bordoff, J., \& Marsters, P. Can coal make a come back? Columbia University, Center on Global Energy Policy (April 2017).

16. U.S. Energy Information Administration. Annual energy outlook 2017 with projections to 2050 (2017).

17. Chu, S., \& Majumdar, A. Opportunities and challenges for a sustainable energy future. Nature 488: 294-303 (2012).

18. Rhodes, J., King, C., Gulen, G., Olmstead, S. M., Dyer, J. S., Hebner, R. E., Beach, F. C., Edgar, T. F., Webber, M. E. A geographically resolved method to estimate levelized power plant costs with environmental externalities. Energy Policy 102: 491-499 (2017).

19. U.S. Energy Information Administration. Planned electric generating unit additions. Electric Power Monthly. January 2017. https://www.eia.gov/electricity/monthly/epm table_grapher.cfm?t=epmt_6_05 (2017).

20. Carley, S., Baldwin, E., MacLean, L. M., \& Brass, J. N. Global Expansion of Renewable Energy Generation: An Analysis of Policy Instruments. Environmental and Resource Economics (2016).

21. International Energy Agency. World Energy Outlook 2016 (2016).

22. Tabuchi, H. Coal mining jobs Trump would bring back no longer exist. The New York Times (March 29, 2017).

23. Douglas, S., \& Walker, A. Coal mining and the resource curse in the eastern United States. Journal of Regional Science 00, 1-23 (2016).

24. Betz, M. R., Partridge, M. D., Farren, M., \& Lobao, L. Coal mining, economic development, and the natural resources curse. Energy Economics 50, 105-116 (2015).

25. Freudenburg, W. R. Addictive Economies: Extractive Industries and Vulnerable Localities in a Changing World. Rural Sociology 57, 305-32 (1992). 
26. Freudenburg, W. R. \& Lisa J. Wilson. Mining the Data: Analyzing the Economic Effects of Mining on Rural Communities. Sociological Inquiry 72, 549-75 (2002).

27. Partridge, M. D., Betz, M. R., \& Lobao, L. Natural Resource Curse and Poverty in Appalachian America. American Journal of Agricultural Economics 95, 449-56 (2013).

28. Black, D., McKinnish, T., \& Sanders, S. Tight labor markets and the demand for education: Evidence from the coal boom and bust. Industrial Labor Relations Review 59, 3-16 (2005).

29. Glasmeier, A. K., Farrigan, T. L. Poverty, sustainability, and the culture of despair: Can sustainable strategies support poverty alleviation in America's most environmentally challenged communities? The ANNALS of the American Academy of Political and Social Science 590, 131149 (2003).

30. Geographic Research, Inc. Business Counts Data 2015. SimplyMap database (2011).

31. Energy Institute. The Full Cost of Electricity (FCe-). The University of Texas at Austin. https://energy.utexas.edu/the-full-cost-of-electricity-fce/ (2017).

32. Energy Institute. Levelized cost of electricity in the United States by County. The University of Texas at Austin. http://calculators.energy.utexas.edu/lcoe map/\#/county/tech (2017).

33. United Nations Framework Convention on Climate Change. Paris Agreement- Status of Ratification. http://unfccc.int/paris agreement/items/9444.php (2017). 


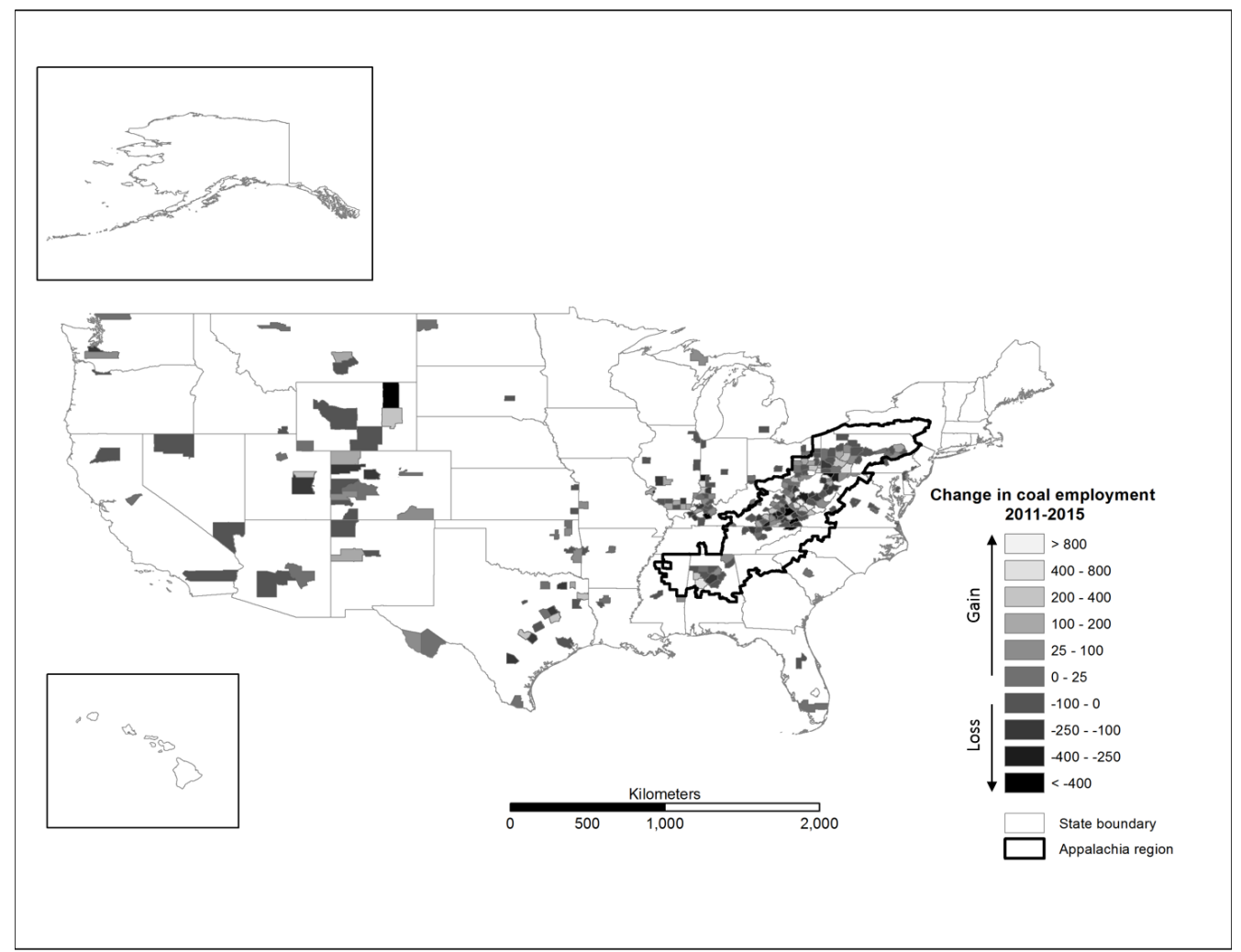

Figure 1. Change in U.S. Coal Employment between 2011 and 2015

Source: ${ }^{30}$ 


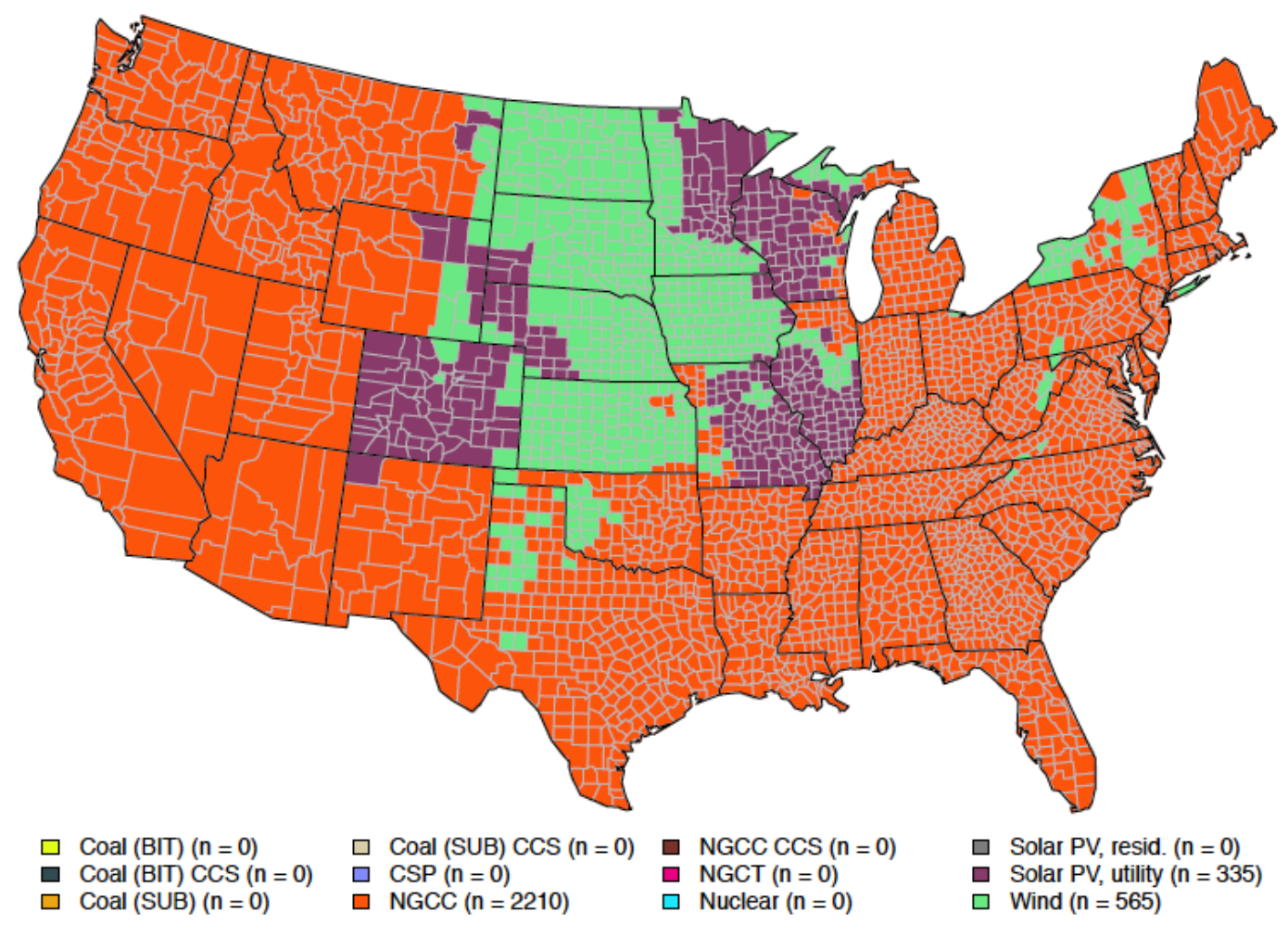

Figure 2. Minimum Levelized Cost of Electricity by Technology and County

Notes: $\mathrm{BIT}=$ bituminous, $\mathrm{CCS}=$ carbon capture and storage, $\mathrm{SUB}=$ subbituminous, $\mathrm{CSP}=$ concentrated solar power, $\mathrm{NGCC}=$ natural gas combined cycle, $\mathrm{NGCT}=$ natural gas combustion turbine, $\mathrm{PV}=$ photovoltaic, resid.=residential, $\mathrm{n}=$ number of times an energy resource appears on the map as a least-cost option.

Source: ${ }^{31,32}$ 


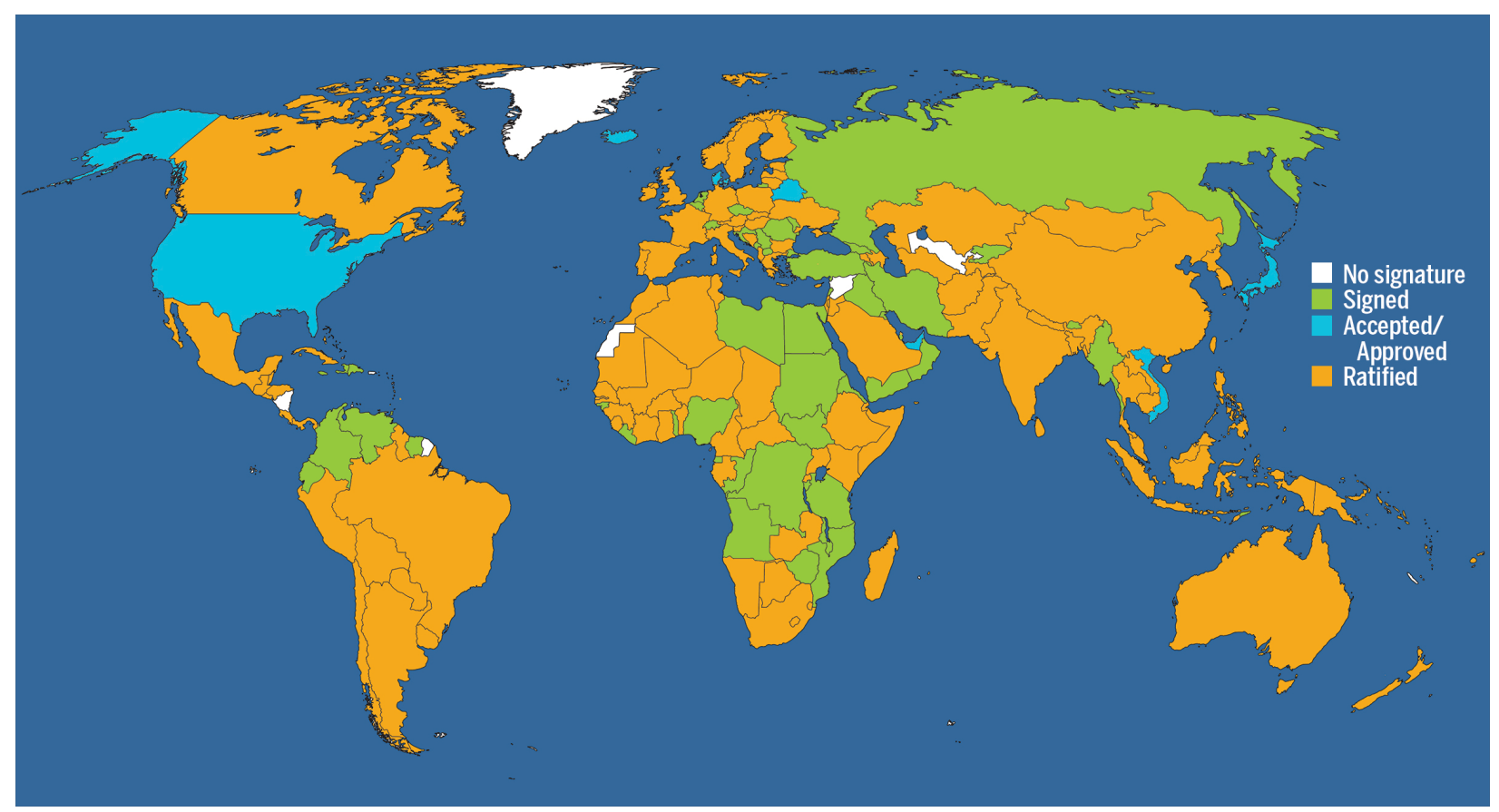

Figure 3. Country Commitments to the Paris Agreement Source: ${ }^{33}$ 

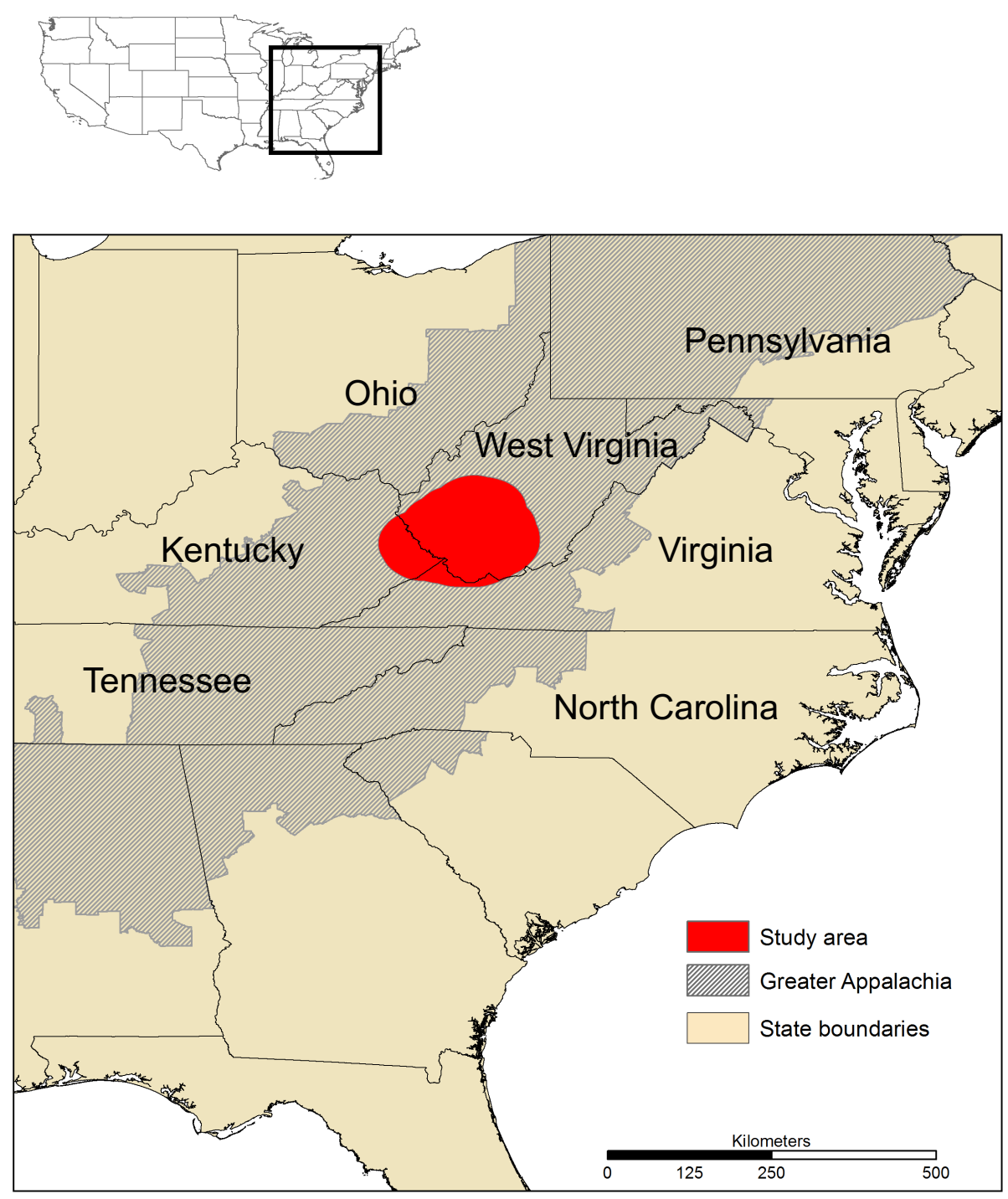

Figure 4. Research Study Area 
Table 1. Focus Group Respondent Descriptive Statistics

\begin{tabular}{lc}
\hline Category & Average or Percent of Total \\
\hline Male & $84 \%$ \\
Age & 33.3 \\
Number of years lived in current community & 27.2 \\
Number in household & 3.8 \\
Income & \\
20k or less & $28 \%$ \\
$21 \mathrm{k}$ to 40k & $20 \%$ \\
$41 \mathrm{k}$ to 60k & $24 \%$ \\
$61 \mathrm{k}$ to 80k & $16 \%$ \\
$80 \mathrm{k}$ and above & $12 \%$ \\
Employment & \\
Currently working & \\
Retired & $20 \%$ \\
Either in training program or not working & $8 \%$ \\
\hline
\end{tabular}


Table 2. Interview Respondent Affiliation

\begin{tabular}{lc}
\hline General Type of Organization in which Interviewee Works & Number of Respondents \\
\hline Economic development organization/council & 7 \\
Social enterprise or activism & 2 \\
Community or religious organization & 1 \\
Technical training/education & 4 \\
Industry seeking employees & 4 \\
Foundation engaged in coal community issues & 1 \\
Analyst and/or academic & 2 \\
Media & 2 \\
Total & $\mathbf{2 3}$ \\
\hline
\end{tabular}




\section{Acknowledgements}

This research is funded by Indiana University's Office of the Vice President for Research. The authors

would like to acknowledge exceptional research assistance provided by Brett Wiley, Michelle Graff, and Linus Platzer. 


\section{Supplementary Information}

Supplementary Table 1. Table of Quotes on Coal as Culture and Community Adaptive Capacity People don't like change, especially around here, they been doing the same thing for 150 years, why would they change now

There is also a sense of grief that comes along with it, you know, coal mining is really a part of the culture here and it's interwoven into the way people feel about themselves and their own identity and their identity as a community. And so to lose that so quickly is really, it creates a sense of grief among people about losing their way of life and a piece of their culture that is really engrained and a part of who they are.

It's a tough transition, it's almost because the area in the past 100, 150 years has been nothing but coal. That's all they know, that's all generations used to know. They've all worked in the mines, they never had to go to college, they'd make just as much as any person in the area. So if somebody tells them to stop doing that, and they're used to making $\$ 120,000$ dollar a year, you can live off $\$ 40,000$ dollars a year job... but they don't know how to. And never had to. It's basically taken away everything they have ever known.

Because to some extent its's everybody who is vulnerable here, that doesn't know how to adjust, but I think the 18-25 kind of ranges because they're just graduating high school, and that's their point to make a decision whether they want to go to college or whether they want to get a job, ah, and it used to, if you want to go to college, great, but if not, you can get a job, a very, very good job, working in the coal mines, support your family for the next 50 years you're alive. Now that's almost not an option, and that takes almost all the options off the table, unless you want to work in fast food or retail, which we don't even have a lot of that.

We were so heavily vested in coal, that, I heard a figure that for every coal miner's job there is ten other jobs that are affected, if not lost.

People in this area... have tunnel vision. They cannot see past coal. They want to elect politicians that are falsely promising them, I'm gonna bring coal back, I'm gonna make West Virginia great again, I'm gonna bring all your coal jobs back. The coal jobs aren't coming back. Coal is dead. And like I said earlier, the reason for this situation is, for a century we have only developed one industry in our state.

And the other, of course, is young people, and you know, for generations, young people, obviously young men, almost overwhelmingly white have been told in those communities, well if you can just get through high school, get that diploma, now you don't need to worry about college and all those kind of stuff, because you can go work at the mine like dad, granddad. And you know, that was very attractive, you can get out of a high school and buy 40,000 dollars, 50,000 dollar pick up truck and marry your girlfriend, buy a big house with a miner's salary. And you now, those days are rapidly disappearing for a larger and larger share of people.

When a coal plant closes, as I'm sure you know, it's removed from the local tax base, right, and oftentimes, these coal plants are the local. So when that revenue goes away, it really impacts local governments and school districts, right. So just, it's interesting, it's one of those problems where the, you know, there are particular communities that are impacted by either the pollution from the coal plant or the whatnot, but really the entire community suffers when a coal plant shuts down. And just to [name removed] point about the problem being comprehensive, this devastates sometimes entire counties or multiple communities. So it does go way beyond just the, I would say the frontline community. It's, I think that's the best way to put it.

A lot of the times at the policy level, everyone talks about jobs, jobs, jobs, and we leave out the human development component that's so important. So if you have someone doing a job that's been in their family, for literally 5 or six generations, your dad did it, your grandfather did it, your great-grandfather 
was a miner... we are not very well positioned to adapt, you know, we have low education levels and poor access to health educators, but having said that, there are a lot of strengths and things that are unique about Appalachia and that we can tap into that for the, for the adaptation.

I feel people are really bitter and nobody has their interest at heart. They feel like the country used them for energy while it bothered them and now that it's done with them, they kind of, like, forget.

I think our state as a whole is particularly vulnerable. Particularly because our political leadership at the state and federal level continues to refuse to engage in promoting new energy industries and so we have, basically, undermined the development of other industries that would compete with the fossil fuel industries even though those are clearly, on a national and international level, the growing industries in the energy sector. There is solar development here in West Virginia but they sell their energy to Maryland because ... Anyway, they are setting us up. That's really putting us in a vulnerable, setting us way behind the starting line and that's all about politics. I think that the folks who are most vulnerable are the people who live in coal communities, and that's not just coal miners, it's business owners, children, women who are having to find second jobs now. These are highly rural, small communities, many of which are isolated geographically.

R1: you know if if you're making bukoos of money and then you go from one day to making a lot to making little of none.

R2: Half. Half, yeah.

R3: Sometimes more than that.

R1: Yeah, it's you don't know how to react and you can't live the same way you were living so you don't know what to cut back or how to cut back or where to cut back or to cut back at all.

R1: I mean at 23 years old, at 23 years old I made $\$ 120,000$ a year as a electrician.

R2: And it's and it's the same industry that my dad was in

R3: And the coal company probably paid for you to become an electrician

R1: Yeah. I didn't pay for anything. I started my life without no debt.

R1: I'll tell you one thing in the county here that's been affected so much is the county the severance money and stuff that the county gets from coal is so far down that... that the town has lost so much revenue. It's unreal.

R2: Well that's what I said we spent we sent all of our severance taxes to Lexington for years and years and years.

R3: Why are they not sending us something back... Now that we need them?

R1: My biggest issue is that I don't have a problem with the transition I really don't as long as we can bring something here that's gonna replace the jobs and the money.

R2: Exactly, if if if our people can have good careers and good good healthy lives and work.

R1: And that's the thing, good, healthy lives, I mean our miners here they dedicate their life and they you know they...

R2: Beaten and broken.

The major manufacturer they are trying to take recruiting seriously, because they don't have the skillsets for modern manufacturing. So you know, coal miners with about even a high school degree, literally even with a high school degree, could be making about 80,000 dollars in a mine. So we don't, we have low higher education rate, we lack a lot of basic life skills, money management skills. You know if you make a lot of money, a lot of them never had to learn the skills to put it away for retirement, so even they have been making 80,000 bucks for ten years, they're broke already, they're out of money. I think that rather than just talking about jobs, we need to talk about human development, you know, health, and education, and that's how we can really build a stronger root system upon the economic development efforts. 


\section{Supplementary Table 2. Table of Quotes on Shifting Mindsets and Seeking New Opportunities}

Honestly, I think most of them are really excited. Cause they understand coming in that this is a good opportunity for them... and they are doing it because of a new technology, a new opportunity, because they see that the coal industry is going down. You could ask a lot of them, and they'll say that. Coal is probably not coming back, or if it is, it's not what it once was, so I'm going to learn as much new and exciting things as I can, I want to get a degree, so I'm more hirable later on.

I'm beginning to see some real enthusiasm, particularly among young people in small communities in West Virginia, to begin looking for something beyond, something beyond coal.

I think slowly but surely, you kind of go through all these stages of mourning. So there's still those that think coal will come back. But there's more than ever in my lifetime many that say it's not coming back, at least not how it was and so there is, definitely more among the younger than among the older, but there is kind of this excitement and possibility, that now coal is gone and we can rebuild our economy into what we want.

The phenomenon ... has been very good to observe. A lot of community groups, a lot of technical systems providers, a lot of university folks, and a lot of nonprofits, and even some businesses that have begun to collaborate now. Around what are the opportunities, possibilities for working in these coalimpacted communities. We...wouldn't have seen this two years ago, much less 5 years ago or 10 years ago. Everybody was in their own domain and weren't necessarily talking to each other... And I think to see positive, sort of small positive successes grows even larger success.

Now we still have political candidates talk about "now let's just bring back coal" well you know, coal is dying, if not dead, at this point. And it will still continue, just not the way it has in the past.

Now, there is a sense that you can want to work for economic transition without it being a judgement statement about what you think about the coal industry or even a moral judgement about the cultural connections to that industry. Of course, you get this but it's a little hard for people to understand if they haven't lived in a place like this before where the culture is so deeply connected to the industry. It becomes a personal attack. There has been a lot of work around dialogue and creating space for conversation about what is next after we move forward from the coal industry. And that was a painful process for many people to accept that there needed to be something next. I think we have in a large part moved through that and people are mostly aware...I think there is actually pretty vast agreement that things are not...the way they are right now whether you think that's caused by energy policies or international economic changes or whatever you think the reason is for things not working. We were in a spot for a long time where that was the whole conversation, "why is it not working?" and "who's fault was it?" and most people are tired of that conversation. Whoever's fault it is, we are the ones who are stuck here who have to fix it so let's just talk about fixing it.

You cannot read a newspaper without seeing the conflict and the contention of issues related to coal and mining and coal impacting the communities. I'm beginning to see some real enthusiasm, particularly among young people in small communities in West Virginia, to begin looking for something beyond, something beyond coal. Not in a negative way, necessarily, but I think the reality has sunk in that there is a lot of strategies that will have to be considered to make that transition successful.

I think when you think about communities, when you think about the people who have been in the mines for years and years, I mean, they are already in transition. People are losing their jobs, people are trying to figure out what are the skills, how to transfer the skills they have to meaningful work activities for their families. There isn't, is not gonna be a silver bullet, it's gonna have to be opportunities, it's gonna be people be trained in a number of areas, it's going to be tough. 
And they think it's always gonna be there. And the money is really good. And I really see the effect of the really good money when I have a student that comes to me and there off on unemployment, they are about to lose their house, you know and they are in a really bad place, and they just didn't- I think that it was easy, it was good money, and it was easy. And they went out and spent a lot of money. I have seen guys with five-and six hundred dollar truck payments, and I have had guys that had to sell off pretty much everything they owned, just to keep going and get through the program. I have seen students that do, some keep chickens, some keep cows, somebody has cut hay. I have seen out in our parking lot, where they are swapping out, and that really does my heart good to see that, because these guys come from different areas, and they may not know each other, but once they are here, they are all banned together. And it think that that's really interesting to see that take place. You know, their pickup trucks will pull out and you see them throwing hay in this one, and this one is bringing in eggs, and this one is bringing in, maybe they have kept cows, or pigs, and they're bringing in meat and switching it.

It's in some ways a really, really great opportunity like that this is happening, which is hard, a really hard thing for me to say at first, knowing how hard it is hitting people here, their lives and their livelihoods. But it's happening no matter what, like what's happening here with the decline of the coal industry, nothing is gonna bring it back to what it was. So we have got to see it as an opportunity to bring the new things to this community, and to be a place, and to be leaders. And community-scale renewable energy, we have such an opportunity to help make our housing stock in the region, which is like some of the worst in the country, much more energy-efficient, and help people save on their energy bills in a way, especially with this on-bill financing, I don't know if you know about that, in ways that help overcome the upfront costs for lower income folks. And in doing that there is saving energy, saving money, but also really improving the quality of the housing, and the health, and the air quality, like indoor air quality and all that, that's an opportunity. And it's an opportunity to really start shifting from this very extractive economy.

But it's sort of hard to figure out what that sort of solution is, and so there has been a lot of smaller efforts that are hard. But still, some people, you know if their parents are moving over to Western Kentucky to do mining over there, it sort of like impacts their family in relation to the job loss. And then it also sort of creates this narrative of us versus them, and in terms of, well you can't be for a clean, just, environmental economy, and at the same time be related to the coal industry. So there is a lot of conflict that I think has been intentionally created by a lot of coal lobbyists, and that sort of thing. But you know, in reality, in my opinion, it's the coal industry's failure for monopolizing this region, for just being a huge greedy corporations, and not actually preparing or caring for their employees to make sure that they are taken care.

I'll add that we have seen a really big narrative shift about the way that coal is talked about in the region and in the state. I mean 8 years ago, probably even less than that, probably 4 years ago, we wouldn't have heard things like out of the mouth of Hal Rogers, who is the $5^{\text {th }}$ District congressman and the chair of the Reparations committee, we would never have heard him say, coal is never going to come back, and now he is saying this publicly, you know, more than once, so it's not a fluke. So it's really interesting to see these elected leaders who previous to this most recent collapse of the industry have really avoided talking about coal decline. And now they are sort of backed up against the wall when ten thousand coal jobs are lost in three years. Where they have, they are being pressured by lots of different people to do something different, to look for alternatives to coal. And that narrative is really huge, and it really helps with the work that we are doing, because we can point to that and say, look here are these powerful people who are, you know, admitting that we have to do something different and we have to find an alternative. So we are trying to do that.

There is also a sense of grief that comes along with it, you know, coal mining is really a part of the culture here and it's interwoven into the way people feel about themselves and their own identity and their identity as a community. And so to lose that so quickly is really, it creates a sense of grief among 
people about losing their way of life and a piece of their culture that is really engrained and a part of who they are...But there is also a sense of opportunity, certainly among certain segments of the population. 


\section{Supplementary Table 3. Word Counts from Interviews and Focus Groups}

\begin{tabular}{lccc}
\hline & Respondent Number of Mentions & $\begin{array}{c}\% \text { of } \\
\text { Interviews }\end{array}$ & $\begin{array}{c}\% \text { of Focus } \\
\text { Groups }\end{array}$ \\
\hline Cultur* (e.g., culture, cultural) & 23 & $45 \%$ & $50 \%$ \\
Communit* (e.g., community, communities) & 386 & $95 \%$ & $100 \%$ \\
Excit* (e.g., excitement, excited) & 21 & $45 \%$ & $0 \%$ \\
Optimis* (e.g., optimism, optimistic) & 5 & $18 \%$ & $0 \%$ \\
Opportunit* (e.g., opportunities, & 80 & $64 \%$ & $100 \%$ \\
opportunity) & & & \\
Adapt* (e.g., adapt, adaptation, adapting) & 33 & $45 \%$ & $0 \%$ \\
Job* (e.g., job, jobs) & 270 & $95 \%$ & $100 \%$ \\
Diversi* (e.g., diversify, diversity) & 18 & $32 \%$ & $50 \%$ \\
Young, younger, or youth & 81 & $59 \%$ & $50 \%$ \\
Rebuil* (e.g., rebuild, rebuilding) & 5 & $9 \%$ & $50 \%$ \\
Enthusias* (e.g., enthusiasm, enthusiastic) & 2 & $5 \%$ & $0 \%$ \\
Vote & 10 & $27 \%$ & $0 \%$ \\
Politics, political, politically & 37 & $50 \%$ & $50 \%$ \\
Elect* (e.g., elect, election) & 13 & $36 \%$ & $50 \%$ \\
\hline
\end{tabular}

